\title{
LA GOBERNANZA GLOBAL DE LA SALUD Y LOS LÍMITES DE LAS REDES DE EXPERTOS EN LA RESPUESTA AL BROTE DE LA COVID-19 EN MÉXICO
}

\author{
GLOBAL HEALTH GOVERNANCE AND THE LIMITATIONS \\ OF EXPERT NETWORKS IN THE RESPONSE TO THE \\ COVID-19 OUTBREAK IN MEXICO
}

\section{GOUVERNANCE MONDIALE DE LA SANTÉ ET LIMITES DES RÉSEAUX D'EXPERTS POUR RÉPONDRE À L'ÉPIDÉMIE DE COVID-19 AU MEXIQUE}

\author{
María Esther Coronado Martínez \\ Facultad de Derecho, UNAM \\ mcoronadom@derecho.unam.mx
}

Resumen: En el presente estudio se argumenta que a partir del sistema de gobernanza global de la salud se han configurado distintas redes de expertos que sirven como mecanismos para la difusión de ideas basadas en la evidencia científica, que promueven la cooperación y la implementación de recomendaciones originadas en la Organización Mundial de la Salud (oms). Sin embargo, el brote de la Covid-19 ha visibilizado las limitaciones de estas redes. En el caso de México, se han observado dos problemas principales: primero, la existencia de expertos miembros de una red transgubernamental que toman decisiones basadas en intereses políticos, dejando de lado las recomendaciones derivadas de lo global; y segundo, una comunidad epistémica dividida, con grupos rivales, lo que perjudica la actuación de estos expertos en su labor como transmisores de ideas y difusores de conocimiento.

Palabras clave: gobernanza global en salud; respuesta pandémica; redes de expertos; Covid-19; México.

ABstract: This study argues that the global health governance system has led to the formation of a number of expert networks that serve as mechanisms for the circulation of evidence-based ideas and that promote cooperation and the implementation of World Health Organization (wHo) recommendations. 
However, the outbreak of Covid-19 has brought to light the limitations of these networks. In the case of Mexico, two principal problems have been observed: first, the existence of experts who belong to a cross-governmental network and who make decisions based on political interest, to the detriment of global recommendations; and second, a divided knowledge community of rival groups that damages the actions of these experts in their efforts to transmit ideas and spread knowledge.

Keywords: global health governance; pandemic response; expert networks; Covid-19; Mexico.

\section{Traducción de Fionn Petch, CM IDiomas}

Résume: Dans cette étude, il est avancé que différents réseaux d'experts ont été configurés à partir du système de gouvernance mondiale de la santé, lesquels servent de mécanismes pour la diffusion d'idées fondées sur des preuves scientifiques, qui favorisent la coopération et la mise en œuvre de recommandations émanant de l'Organisation Mondiale de la Santé (oms). Cependant, l'épidémie de Covid-19 a rendu visibles les limites de ces réseaux. Dans le cas du Mexique, deux problèmes principaux ont été observés: premièrement, l'existence d'experts membres d'un réseau transgouvernemental qui prennent des décisions fondées sur des intérêts politiques, en laissant de côté les recommandations issues du global; et deuxièmement, une communauté épistémique divisée, avec des groupes rivaux, qui mine la performance de ces experts dans leur travail de transmetteurs d'idées et de diffuseurs de connaissances.

Mots clefs: gouvernance mondiale de la santé ; réponse à la pandémie ;

réseaux d'experts ; Covid19; Mexique.

Traducción de Rafael Segovia, CM Idiomas

Fecha de recepción: septiembre de 2020.

Fecha de aceptación: marzo de 2021. 


\section{INTRODUCCIÓN}

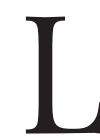

a pandemia de Covid-19 reafirma el efecto que la globalización está teniendo en la transmisión de enfermedades infecciosas, así como la necesidad de crear y proveer bienes públicos globales. Después del brote de sARs en 2003 se inició un proceso de actualización de las normas internacionales centrales para la preparación y respuesta a pandemias, mismo que culminó con la firma del actualizado Reglamento Sanitario Internacional (RSI) en 2005, instrumento que por sí mismo sólo ha generado algunos cambios en el sistema. El RSi 2005 se empleó por primera vez en 2009 para responder a la pandemia de influenza $\mathrm{H} 1 \mathrm{~N} 1$, con algunos resultados positivos, aunque aún sin alcanzar una implementación total. En el caso del brote de la Covid-19, los alcances de esta normatividad han sido limitados por un sistema internacional desarticulado, con la participación de múltiples actores estatales y no estatales, y donde se han generado muchas respuestas nacionales poco coordinadas a nivel global.

El propósito de este trabajo es examinar la implementación de las normas y recomendaciones originadas desde la Organización Mundial de la Salud (oms) en la respuesta de México a la Covid-19. Dada la necesidad de contar con los conocimientos técnicos y científicos para enfrentar los desafíos de fenómenos como las pandemias, el análisis se enfoca en la función de redes de expertos en la transmisión y difusión de recomendaciones internacionales derivadas del diálogo global. Ante las pandemias, los expertos son centrales para guiar la respuesta internacional, por lo que resulta pertinente preguntar ¿por qué las recomendaciones generadas a nivel global durante el brote de la Covid-19, difundidas y transmitidas a través de las redes de expertos, no han sido completamente implementadas en el caso de México? La hipótesis es que, aunque dichas redes son clave en la implementación de recomendaciones en la respuesta sanitaria ante la Covid-19, en México los actores nacionales vinculados 
a las redes de expertos han enfrentado problemas debido a la falta de cohesión y de consensos, así como ante la interferencia política, que afecta su legitimidad. Lo anterior ha causado deficiencias en la difusión de las recomendaciones internacionales para guiar la respuesta del país.

Para analizar los mecanismos que intervienen en la forma en que las redes de expertos en México influyen en la toma de decisiones que ha determinado la respuesta a la pandemia de la Covid-19, este artículo recurre al estudio de caso, ${ }^{1}$ metodología comúnmente utilizada en este tema. ${ }^{2}$ Para dicho objetivo, el presente trabajo se ha estructurado en cuatro secciones: la primera introduce el marco teórico sobre las redes de expertos, la segunda explica cómo funcionan estas redes a nivel global y en el caso de México, la tercera presenta más ampliamente la situación mexicana en el contexto de la Covid-19.

\section{LAS REDES DE EXPERTOS EN LA GOBERNANZA GLOBAL} DE LA SALUD

Desde una visión constructivista, parte de la política global se explica debido a las diferencias en los procesos de aprendizaje y las diversas formas en que los gobiernos adoptan y utilizan modelos de políticas públicas. ${ }^{3}$ Los Estados adopta-

1 Peter Haas, Epistemic Communities, Constructivism, and International Environmental Politics, Nueva York, Routledge, 2015, p. 7.

${ }^{2}$ George Alexander y Andrew Bennett, Case Studies and Theory Development in Social Sciences, Cambridge, MIт Press, 2005; Michael Karlsson, "Epistemic Communities and Cooperative Security: The case of Communicable Disease Control in the Baltic Sea Region”, Journal of International and Area Studies, vol. 11, núm. 1, 2004, pp. 79-100; Mai'a K. Davis Cross, "Rethinking Epistemic Communities Twenty Years Later", Review of International Studies, vol. 39, num. 1, 2013, pp. 137-160.

3 Arild Underdal, "Explaining Compliance and Defection: Three Models", European Journal of International Relations, vol. 4, núm. 1, 1998, pp. 5-30; Peter Haas, "Epistemic Communities and International Policy Coordination”, International Organization, vol. 46, núm. 1, 1992, pp. 1-35. 
rán e implementarán políticas prescritas internacionalmente en la medida en que sean modelos convincentes para actores estatales y que puedan usarse para persuadir a otros. ${ }^{4}$ El proceso de difusión y transferencia implica que ciertas instituciones, políticas y conocimientos a nivel global se utilizan en el desarrollo de instituciones y políticas en otro momento y lugar. ${ }^{5}$ El conocimiento es visto como una variable que afecta el comportamiento del Estado y el resultado de decisiones se basa en información, ciencia e ideas, ${ }^{6}$ donde los actores no estatales, como las redes de expertos, son esenciales. $^{7}$

La gobernanza global en salud (GGS), definida como un sistema de normas e instituciones que atiende los problemas que son comunes entre los Estados y los seres humanos, ${ }^{8}$ retoma estas ideas, poniendo énfasis en el papel e interacciones de los Estados y los actores no estatales. ${ }^{9}$ En el centro de

${ }^{4}$ Alexander Wendt, "Anarchy Is What States Make of it: The Social Construction of Power Politics", International Organization, vol. 46, núm. 2, 1992, pp.391-425; Kurt Weyland, "The Puzzle of Policy Diffusion”, Bounded Rationality and Policy Diffusion: Social Sector Reform in Latin America, Princeton, University Press, 2006, pp. 1-29.

${ }^{5}$ Diane Stone, "Transfer and translation of policy", Policy Studies, vol. 33, núm. 6, 2011, pp. 483-499.; Mark Evans, "Understanding Policy Transfer", en Mark Evans (ed.), Policy Transfer in Global Perspective, Aldershot, Ashgate, 2004, pp. 10-42.

${ }^{6}$ Peter Haas, "When Does Power Listen to Truth? A Constructivist Approach to the Policy Process", Journal of European Public Policy, vol. 11, núm. 4, 2004, pp. 569-592.

${ }^{7}$ Jane Jenson, "Diffusing Ideas for After Neoliberalism: The Social Investment Perspective in Europe and Latin America", Global Social Policy, vol. 10, núm. 1, 2010, pp. 59-84; Peter Haas, "Epistemic Communities and International Policy Coordination”, art. cit., p. 5; Diane Stone, art. cit., pp. 486-487.

${ }^{8}$ Kelly Lee y Adam Kamradt-Scott, "The Multiple Meanings of Global Health Governance: A Call for Conceptual Clarity", Globalization and Health, vol. 11, 2014, pp. 10-28.

${ }^{9}$ Mark W. Zacher y Tania J. Keefe, The Politics of Global Health Governance. United by Contagion, Nueva York, Palgrave Macmillan, 2007; Julio Frenk y Sue Moon, "Governance Challenges in Global Health", New England Journal of Medicine, vol. 368, núm. 10, 2013, pp. 936-942. 
la GGS están la oms y sus oficinas regionales, como la Organización Panamericana de la Salud (ops), las cuales funcionan como actores técnicos tratando de construir un consenso internacional en la política de salud global. Para ello, usan redes de expertos, comunidades epistémicas y redes transgubernamentales, como herramientas de transferencia y difusión de políticas globales, ${ }^{10}$ así como agentes catalizadores de cooperación y facilitadores de la transferencia y difusión de políticas y recomendaciones.

Una comunidad epistémica se define como "una red de profesionales, de una variedad de disciplinas y orígenes, con experiencia y competencia reconocidas en un área en particular y que son considerados autoridades relevantes para las políticas dentro de ese dominio o área temática". ${ }^{11}$ Son profesionales que comparten nociones de validez, un lenguaje y una cultura en común; así como creencias normativas, creencias causales, criterios epistemológicos y un entendimiento conjunto de las políticas. ${ }^{12}$ La teoría de las comunidades epistémicas considera que estos actores pueden mejorar la cooperación internacional ${ }^{13}$ especialmente cuando se enfrentan problemas globales complejos, que generan un alto grado de incertidumbre y para los cuales las personas responsables de tomar decisiones buscan en los expertos ideas

${ }^{10}$ Jorge E. Culebro, "Gestión de crisis y retos para el sistema de salud. La coordinación vertical y horizontal para los sistemas de salud en México", Reporte CESOP núm. 132, edición especial, 2020, p. 47.

11 Peter Haas, "Epistemic Communities and International Policy Coordination", art. cit., p. 3.

${ }^{12}$ Loc. cit., Jean-Frédéric Morin, "Paradigm Shift in the Global IP Regime: The Agency of Academics", Review of International Political Economy, vol. 21, núm. 2, 2014, pp. 275-309.

${ }^{13}$ Michael Karlsson, art. cit., p. 79-100; Mai'a K, Davis Cross, Security Integration in Europe: How Knowledge-Based Networks Are Transforming the European Union, Ann Arbor, University of Michigan Press, 2011; Jeremy Shiffman, et al., "A Framework on the Emergence and Effectiveness of Global Health Networks", Health Policy and Planning, vol. 31, sup. 1, 2016, pp. i3-i16. 
y respuestas para resolverlos. ${ }^{14}$ Las comunidades epistémicas son redes de conocimiento que conectan múltiples actores, creando alianzas interorganizacionales y generando lazos estrechos entre sus miembros. ${ }^{15} \mathrm{Su}$ organización facilita el proceso de trasmisión y difusión de ideas para que se adopten en diferentes contextos ${ }^{16}$ y su conexión con actores externos, y con otras redes de expertos. ${ }^{17}$

Una de las críticas sobre las comunidades epistémicas es la poca claridad en cuanto a los mecanismos por medio de los cuales influyen en el proceso de toma de decisiones, ${ }^{18}$ en parte porque es difícil definir quiénes son los miembros de éstas. El tipo de miembros que integran estas redes han sido descritos de forma reducida refiriéndose generalmente a científicos y académicos, ${ }^{19} \sin$ embargo, las comunidades epistémicas pueden estar compuestas por expertos de distin-

${ }^{14}$ Peter Haas, "When Does Power Listen to Truth?”, art. cit., p. 569; Mai'a K. Davis Cross, "Rethinking Epistemic Communities Twenty Years Later", art. cit., pp. 137-160; Ole J. Sending, "Knowledge Networks, Scientific Communities, and Evidence-Informed Policy", en Diane Stone and Kim Moloney (eds.), Global Policy and Transnational Administration, Oxford, University Press, 2019, p. 386; Andreas Antoniades, "Epistemic Communities, Epistemes and the Construction of World Politics", Global Society, vol. 17, núm. 1, 2003, pp. 21-38.

${ }^{15}$ James K. Sebenius, "Challenging Conventional Explanations of International Cooperation: Negotiation Analysis and the Case of Epistemic Communities", International Organization, vol. 46, núm. 1, 1992, pp. 323365; Michael Karlsson, art. cit., pp. 79-81.

${ }^{16}$ Peter Haas, "When Does Power Listen to Truth?", art. cit., p. 572.

17 Margaret Keck y Kathryn Sikkink, "Transnational Advocacy Networks in International and Regional Politics", en Activists Beyond Borders, Ithaca, Cornell University Press, 1998, pp. 1-38; Michael Karlsson, art. cit., pp. 79-100.

${ }^{18}$ David Toke, "Epistemic Communities and Environmental Groups", Politics, vol. 19, num. 2, 1999, p. 101; Ronald R. Krebs, "The Limits of Alliance: Conflict, Cooperation, and Collective Identity", en Anthony Lake y David Ochmanek (eds.), The Real and the Ideal: Essays on International Relations in Honor of Rich, Lanham, Rowman \& Littlefield Publishers, 2001, pp. 225-226.

${ }^{19}$ Mai'a K. Davis Cross, "Rethinking Epistemic Communities Twenty Years Later", art. cit., pp. 137-160. 
tos ámbitos, científicos, académicos, burócratas nacionales e internacionales, analistas de políticas públicas o científicos sociales que a veces trabajan de forma independiente, en universidades u organizaciones no gubernamentales. Muchos de estos actores son parte directa del sistema de gobernanza, sus Estados, organizaciones, sus normas e instituciones. En este sentido, puede considerarse que algunos integrantes de estas comunidades son al mismo tiempo parte de una red transgubernamental, especialmente en áreas de la administración pública donde se necesita un alto nivel de conocimiento técnico para la toma de decisiones.

De acuerdo con Timothy Legrand, cuando se enfrentan problemas de naturaleza global, los gobiernos participan en un proceso de gestión más allá de lo nacional, donde las redes transgubernamentales son esenciales para enfrentarlos. ${ }^{20}$ Tales redes son identificadas como expertos y responsables de tomar decisiones con capacidad de movilizar recursos y poder en sus Estados de origen, cuya comunicación facilita la transferencia de ideas más allá de las fronteras nacionales, a partir de objetivos normativos y valores en común. ${ }^{21}$ Estos actores tienen acceso a información primordial y pueden influir de forma directa en la toma de decisiones, dado que tienen contacto con sus pares tanto a nivel nacional como internacional y pueden colaborar a través de procesos formales e informales para resolver problemas colectivos. ${ }^{22}$ Estas redes sirven como instrumentos en el sistema de gobernanza para intercambiar ideas e información, y coordinar políticas sin tener que acudir a meca-

20 Timothy Legrand, "Transgovernmental Policy Networks in the Anglosphere”, Public Administration, vol. 93, núm. 4, 2015, p. 206; Diane Stone y Stella Ladi, "Global Public Policy and Transnational Administration”, Public Administration, vol. 93, núm. 4, 2015, pp. 839-855.

${ }^{21}$ Ole J. Sending, art. cit., p. 389; Timothy Legrand, "Sovereignty Renewed: Transgovernmental Policy Networks and the Global Local Dilemma", en Diane Stone y Kim Moloney (eds.), Global Policy and Transnational Administration, Oxford, University Press, 2019, pp. 200-222.

22 Timothy Legrand, art. cit., pp. 201-205. 
nismos más formales. ${ }^{23}$ Se puede considerar que una red transgubernamental es un subgrupo dentro de una comunidad epistémica, por estar directamente vinculado con ésta, pero al mismo tiempo, con capacidad para actuar sin involucrar directamente a otros miembros en la comunidad. Al identificarlos de esa manera, se establece de forma directa un enlace al proceso de políticas públicas y un vínculo más directo entre la comunidad y los responsables de tomar decisiones, lo que permite influir en la definición y adopción de políticas en cualquier nivel. Vincular estos dos conceptos, además, facilita analizar la forma en que las comunidades consolidan su poder burocrático, así como su capacidad para institucionalizar su influencia e insertar su punto de vista en el proceso político. ${ }^{24}$

En la literatura se han identificado diversos problemas a los que se enfrentan las comunidades epistémicas, desde su estructura y la necesidad de consolidarse como un grupo con cohesión interna y profesionalismo, que logra alcanzar consensos entre sus miembros, ${ }^{25}$ hasta el ejercicio de poder de los científicos al emitir juicios de valor y no aislarse de la influencia política, lo que afecta su legitimidad social. ${ }^{26} \mathrm{Se}$ reconoce que los grupos de expertos son más fuertes e influyentes cuando son homogéneos y cohesivos, y con creencias sólidas. ${ }^{27}$ Esto se logra si ocurre un proceso de socialización

${ }^{23} \mathrm{Ibid}$, p. 212.

${ }^{24}$ Andreas Antoniades, art. cit., pp. 21-30.

${ }^{25}$ Mai'a K. Davis Cross, "Rethinking Epistemic Communities Twenty Years Later", art. cit., p. 147.

${ }^{26}$ Konrad Späth, "Inside Global Governance: New Borders of a Concept", en Markus Lederer y Phillip Muller (eds.), Criticizing Global Governance, Nueva York, Palgrave Macmillan, 2005, p. 38; Timothy Legrand, art. cit., p. 974; Ole J. Sending, art. cit., pp. 383-400; Peter Haas, "Epistemic Communities and International Policy Coordination", art. cit., pp. 1-35.

${ }_{27}$ Mai'a K. Davis Cross, "Rethinking Epistemic Communities Twenty Years Later", art. cit., pp. 137-160; James K. Sebenius y David A. Lax, "Interests: The Measure of Negotiation”, Negotiation Journal, vol. 2, núm. 1, 1986, pp. 73-92. 
de las ideas entre miembros de una comunidad epistémica, lo que les permite generar consensos sobre un problema. Sin embargo, el conocimiento está en constante disputa y los desacuerdos entre los expertos son comunes. ${ }^{28}$ Por ello existen grupos rivales dentro de un mismo debate temático, lo que perturba el proceso de formulación de políticas, puesto que el conocimiento impugnado es difícil de traducir en políticas o acciones claras y convincentes. ${ }^{29}$ De la misma manera, las divergencias entre expertos pueden tener repercusiones en la legitimidad de las decisiones que se derivan de estos grupos. ${ }^{30}$

A pesar de estos límites, la conexión entre comunidades epistémicas y redes transgubernamentales permite entender mejor el mecanismo mediante el cual las primeras logran influir en el proceso de toma de decisiones. No obstante, esta conexión entre grupos de expertos los integra más a los procesos de la política nacional, volviéndolos también más susceptibles a influencias políticas que afectan su posición como autoridades en un tema, dado que su actuación en el sistema de gobernanza global no es independiente de las dinámicas del Estado. Por lo tanto, también es necesario considerar que, aunque el poder y el conocimiento generalmente se tratan como alternativas competitivas, ya que la ciencia y la política obedecen a principios diferentes, cuando las comunidades epistémicas reclaman su papel de autoridades en un área de conocimiento, ejercen cierto tipo de p. 389 .

${ }^{28}$ Jean-Frédéric Morin, art. cit., p. 280; Andreas Antoniades, art. cit.

${ }^{29}$ Jeremy Youde, "The Development of a Counter-Epistemic Community: AIDS, South Africa, and International Regimes", International Relations, vol. 19, núm. 4, 2005, pp. 421-439.

30 Anne-Marie Slaughter y David T. Zaring, "Networking Goes International: An Update", Annual Review of Law $\mathcal{E}$ Social Science, vol. 2, 2006, pp. 220-224; Grace Skogstad, "Legitimacy and/or Policy Effectiveness? Network Governance and GMO Regulation in the European Union", Journal of European Public Policy, vol. 10, núm. 3, 2003, pp. 323-327. 
poder. ${ }^{31}$ Las consecuencias distributivas de los consejos basados en la ciencia son en sí mismas políticas, porque se dan en un proceso de negociación con actores políticos y gobierno donde, en muchas ocasiones, la política se superpone a la evidencia científica. ${ }^{32}$

En el caso de la Covid-19 se han observado múltiples ejemplos de estas problemáticas, como las divergencias en la comunidad epistémica internacional por la existencia de desacuerdos entre los expertos de la oms y los que no están afiliados directamente a la organización. Aquí destaca la polémica sobre la transmisión aérea del virus. Aunque actualmente se reconoce esta vía como el principal medio de contagio, en julio de 2020, un grupo de 239 científicos solicitaron cambiar la estrategia internacional, presentando evidencia clara del contagio por medio del efecto aerosol en espacios cerrados, con lo que pedían poner mayor énfasis en las medidas para mitigar la transmisión por este medio. ${ }^{33}$ El llamado de estos científicos tenía como objetivo que los expertos de la oms revisaran la evidencia y modificaran las recomendaciones emitidas, lo cual ocurrió de forma inmediata. ${ }^{34}$

En el caso de la influencia política, la pandemia ha exacerbado los sentimientos de insatisfacción de la población por la ciencia y la evidencia que ésta produce, impulsados en parte por la ola de desinformación que ha habido. Lo anterior ha influido en que muchos gobiernos decidan hacer caso omiso de las recomendaciones guiadas por la evi-

31 James K. Sebenius, art. cit., p. 325; Giandomenico Majone, Evidence, Argument, and Persuasion in the Policy Process, New Haven, Yale University Press, 1989, p. 3.

${ }^{32}$ Susan Cozzens y Edward Woodhouse, "Science, Government, and the Politics of Knowledge", en Sheila Jasanoff, et al. (eds.), Handbook of Science and Technology Studies, Thousand Oaks, Sage Publications, 1995, pp. 532-553.

${ }^{33}$ Lidia Morawsk y Donald K. Milton, "It Is Time to Address Airborne Transmission of Coronavirus Disease 2019 (COVID-19)", Clinical Infectious Diseases, vol. 71, núm. 9, 2020, pp. 2311-2313.

34 Apoorva Mandavilli, "W.H.O. to Review Evidence of Airborne Transmission of Coronavirus", The New York Times, 6 de julio de 2020. 
dencia, perjudicando el trabajo de difusión de los expertos. ${ }^{35}$ Por ejemplo, en el caso de Brasil, desde el inicio de la epidemia, los expertos nacionales de la comunidad epistémica han tenido que enfrentar muchos problemas para aplicar medidas surgidas desde lo global. Éste es el caso de los exministros de Salud, Luiz Henrique Mandetta (enero de 2019-abril de 2020) y Nelson Teich (abril-mayo de 2020), quienes tuvieron que defender las medidas basadas en evidencia científica enfrentándose directamente al presidente Jair Bolsonaro y su postura de minimización de la pandemia. En este caso, a pesar de que los exministros son miembros directos de una red transnacional y, en teoría, tienen la posibilidad de influir en la toma de decisiones para diseminar políticas globales, sus recomendaciones al final no fueron aceptadas por el jefe de Estado, y renunciaron a sus cargos. ${ }^{36}$

Otro ejemplo es Estados Unidos, particularmente con la relación entre el expresidente Donald Trump (20172021) y el grupo de científicos que integraron el Grupo de trabajo sobre el Coronavirus de la Casa Blanca (White House's Coronavirus Task Force). Desde muy al prinicipio en la pandemia aparecieron señales de desacuerdo, en especial con el líder del grupo, el Dr. Anthony Fauci. ${ }^{37}$ Este último, un reconocido experto en enfermedades infecciosas con un vínculo muy cercano a la comunidad epistémica global, muchas veces fue cuestionado por el presidente por respaldar lineamientos derivados de un consenso internacional, pero que no resonaban con los intereses políticos

35 Nic Fleming, "Coronavirus Misinformation, and How Scientists Can Help to Fight it", Nature, 17 de junio de 2020; Richard Horton, "Offline: Science and Politics in the Era of COVID-19", The Lancet, vol. 396, núm. 10259, 2020, p. 1319.

36 Pedro C. Hallal, "SOS Brazil: Science under Attack", The Lancet, vol. 397, núm. 10272, 2021, pp. 373-374.

37 Savannah Behrmann y Jeanine Santucci, "Here's a Timeline of President Donald Trump's and Dr. Anthony Fauci's Relationship”, USA Today, 28 de octubre de 2020. 
del entonces mandatario. ${ }^{38} \mathrm{Al}$ final, esto ocasionó que el Dr. Fauci fuera a menudo relegado y se desatenieran sus recomendaciones, generando divisiones entre los expertos del país, lo cual afectó también la capacidad de la comunidad epistémica nacional para influir en las políticas. En este ejemplo, nuevamente, vemos que cuando las recomendaciones basadas en evidencia emanada de la comunidad global no resuenan con los intereses políticos, se reduce la capacidad de los expertos en la difusión y transmisión de políticas. ${ }^{39}$ México también es un caso para el cual se identifican problemas en la adopción de políticas globales trasmitidas y difundidas a través de la comunidad epistémica, argumento que se profundizará en la siguiente sección.

EL FUNGIONAMIENTO DE LAS REDES DE EXPERTOS EN EL SISTEMA DE GOBERNANZA GLOBAL DE LA SALUd EN MÉXico Y LA PANDEMIA DE COVID-19

En la respuesta internacional a un brote epidémico es necesaria la implementación coordinada de medidas de salud pública, en cuyo proceso los expertos se vuelven esenciales en la aplicación de la normatividad, lo que a su vez consolida la definición de políticas surgidas de la GGs. ${ }^{40}$ El RSI 2005 es el acuerdo internacional vigente que guía tal respuesta. Aunque la normatividad internacional no menciona explícitamente las redes de expertos como actores, les asigna un papel primario, y su asesoría a partir de la evidencia científica que sustentan es requerida para la implementación de las normas

${ }^{38}$ Donald Mc. Niel, "Un zorrillo en el picnic: Anthony Fauci habla de cómo fue trabajar para Trump", The New York Times, 26 de enero de 2021.

${ }^{39}$ Stevens, Alex, "Survival of the Ideas that Fit: An Evolutionary Analogy for the Use of Evidence in Policy", Social Policy and Society, vol. 6, núm. 1, pp. 25-35.

${ }^{40}$ Organización Mundial de la Salud, oms, Reglamento Sanitario Internacional 2005, Ginebra, 2008. 
durante una pandemia. ${ }^{41}$ Por ejemplo, el artículo 12 del RsI 2005 define que un Comité de Expertos (CE) es el principal ente técnico para la evaluación de un brote epidémico. El CE tiene el papel de asesor del Director General de la OMs (DG) y recomendará si un evento deberá o no ser declarado "Emergencia de Salud Pública de Importancia Internacional" (ESPII). Además, se indica que la oms y su DG deberán considerar los principios científicos, la evidencia científica disponible y la información en la evaluación de un brote, y todos los diferentes componentes de la respuesta. ${ }^{42}$ En el artículo 47 se estipula que el DG debe establecer una "Lista de Expertos" en todos los campos relevantes al Rsi $2005 .{ }^{43}$ Éstos serán llamados a participar en una CE cuando sea necesario. El artículo 49 establece que el DG deberá seleccionar de la lista de expertos a quienes integrarán el cE en función de "su campo de especialización y experiencia más relevante para el evento específico que está ocurriendo". ${ }^{44}$ A partir de estos mecanismos se determinan las acciones y lineamientos internacionales que serán transmitidos y diseminados por las redes de expertos a nivel nacional.

México, como miembro fundador de la oms -actualmente uno de los 15 mayores contribuyentes $-{ }^{45}$, y de la ops, tiene acceso y participa mediante sus expertos en estos grupos. Esto le permite conectarse a la comunidad epistémica internacional y a redes transgubernamentales por las que se difunden las decisiones y políticas globales. Un primer grupo

${ }^{41}$ Además, por primera vez se incluye la posibilidad de que otros actores no estatales o individuos hagan reportes a la oms sobre la probable aparición de casos de alguna enfermedad con potencial pandémico o de una nueva enfermedad, ver artículo 9 del Reglamento Sanitario Internacional.

${ }^{42}$ Ibid., pp. 14-15.

${ }^{43}$ Ibid., p. 31.

44 Ibid., p. 32.

45 Organización Mundial de la Salud, oms, "Status of Collection of Assessed Contributions, Including Member States in Arrears in the Payment of their Contributions to an Extent that Would Justify Invoking Article 7 of the Constitution", Resolución A72/23, 2020, p. 8. 
consiste en los expertos mexicanos que tienen un sitio asegurado por su posición en la burocracia nacional y que son designados por el gobierno. Desde la aprobación del RSI 2005, durante cada sexenio, México suele solicitar la integración de mexicanos a la lista de expertos del Rsi, generalmente funcionarios de la Secretaría de Salud. Cabe destacar que los miembros de la lista pueden ser o no llamados a colaborar con la oms. ${ }^{46}$ Un segundo grupo son otros expertos fuera de la administración pública mexicana que son invitados directamente por la oms, y que en algunos casos deben contar con el beneplácito del gobierno. El cuadro 1 presenta algunas de las personas que han sido integradas a estos grupos.

En el contexto de la pandemia de Covid-19, se identifica a la comunidad epistémica a partir del grupo formado por los expertos de todo el mundo que integran el Comité de Emergencia de la oms. México no cuenta con ningún representante en dicho grupo, sin embargo, sus principales socios comerciales, Estados Unidos y Canadá sí participan en él. El primero con el director de Migración y Cuarentenas de los Centros para el Control y la Prevención de Enfermedades (CDC por sus siglas en inglés) y el segundo fue inicialmente representado por la jefa de la Agencia de Salud Pública (PHAC por sus siglas en inglés). Esto es importante para México, ya que ha construido una importante relación de trabajo con estos países a través de redes transgubernamentales, entre las cuales destacan el North American Plan for Avian and Pandemic Influenza, NAPAPI (Plan para la Influenza Aviar y Pandémica en América del Norte) creado después del brote de sARs, y la Iniciativa Global para la Seguridad Sanitaria (Global Health Security Initiative-GHSI), establecida después de los ataques bioterroristas de 2001 en Estados Unidos, y la cual ha colaborado de forma muy cer-

46 Carta de la oms con fecha del 11 de junio de 2020, dirigida al Dr. López-Gatell, compartida por Jenaro Villamil a través de Twitter, https://twitter.com/jenarovillamil/status/1271547479725682691?s=20; "López-Gatell, nuevo miembro del comité de expertos de la oms", Aristegui Noticias, 12 de junio de 2020. 
cana a la oms para elaborar diversas políticas. ${ }^{47}$ Estos mecanismos conectan a la región con el ámbito global, facilitando la transferencia de políticas y la diseminación de información en la toma de decisiones.

\section{CUAdro 1}

Expertos mexicanos que han formado parte de los comunidades epistémicas y redes transgubernamentales conectadas a la oMs

\begin{tabular}{|l|l|c|}
\hline \multicolumn{1}{|c|}{ Experto } & \multicolumn{1}{|c|}{ Grupo } & Año \\
\hline Dr. Gerardo Varela & Miembro de la red de centros para influenza & 1952 \\
\hline Dr. José Ignacio Santos & Global Initiative on Sharing Avian Influenza Data (GISAID) & 2010 \\
\hline Dr. Rogelio Pérez Padilla & Comité de Emergencia Influenza H1N1 & 2009 \\
\hline Dr. Hugo López-Gatell & Comité Revisión de la Respuesta ante la Influenza H1N1 & 2011 \\
\hline Dr. Julio Frenk & $\begin{array}{l}\text { OMs Panel Interino de Evaluación de la Repuesta ante el } \\
\text { Ébola }\end{array}$ & 2015 \\
\hline
\end{tabular}

Fuentes: elaboración propia con fuentes varias. ${ }^{\mathrm{a}}$

a A. M.-M., Payne, "The Influenza Programme of WHO”, Bulletin of the World Health Organization, núm. 8, 1953, pp. 755-774; Organización Mundial de la Salud, oms, Report of the Review Committee on the Functioning of the International Health Regulations (2005) about Pandemic Influenza (H1N1) 2009, Documento A64/105, 2011, p. 77; Organización Mundial de la Salud, oms, Strengthening Response to Pandemics and other Public Health Emergencies, Documento A64/10, IHR Review Committee, 2011; Organización Mundial de la Salud, oms-Panel de Expertos Independientes, Report of the Ebola Interim Assessment Panel, julio de 2015.

Aunque es imposible nombrar a todos los expertos que pueden estar vinculados actualmente a estas redes -por su informalidad relativa-, cabe destacar que México nombró como líder de la respuesta nacional al Dr. Hugo López-Gatell, subsecretario de Prevención y Promoción de la Salud y quien, de

${ }^{47}$ Por ejemplo, véase de la Organización Mundial de la Salud, oms, Epidemic Intelligence from Open Sources EIOS, https://www.who.int/ initiatives/eios (consulta del 20 de enero de 2021). 
acuerdo con el artículo 47 del RSI 2005, fue integrado a la lista de expertos el pasado 11 de junio de $2020 .{ }^{48}$ El subsecretario tiene una amplia trayectoria en el tema; por ejemplo, estuvo involucrado en la respuesta a la influenza pandémica H1N1 en 2009, contribuyendo a la revisión de la respuesta mundial ante dicha enfermedad (véase cuadro 1), además de colaborar también directamente en las redes transgubernamentales anteriormente mencionadas.

La participación de expertos mexicanos en dichos grupos los vincula con una comunidad epistémica internacional y una red transgubernamental, lo que en teoría incrementa su capacidad para influir en la adopción de políticas nacionales derivadas de directrices globales. Sin embargo, como analizaremos en el siguiente apartado, en México, la respuesta nacional a la Covid-19 no siempre se ha adherido a los lineamientos planteados desde lo global.

\section{LA GOBERNANZA GLOBAL DE LA SALUD EN EL CASO DE LAS PANDEMIAS y LA RESPUESTA DE MÉXico ANTE LA Covid-19}

El 31 de diciembre de 2019, China notificó a la oms de la existencia de un brote de neumonía atípico en la Ciudad de Wuhan. ${ }^{49}$ De acuerdo con el Rsi 2005, se integró un CE para la Covid-19, mismo que después de su reunión del 30 de enero de 2020 recomendó al DG de la OMs declarar el brote una ESPII, ${ }^{50}$

${ }^{48}$ Carta de la oms, 11 de junio de 2020, loc. cit.

${ }^{49}$ Eduardo López-Ortiz, et al., "From the Handling of an Outbreak by an Unknown Pathogen in Wuhan to the Preparedness and Response in the Face of the Emergence of Covid-19 in Mexico", Gaceta Médica de México, vol. 156, núm 2, 2020, p. 133.

50 Organización Mundial de la Salud, oms, "Statement on the Second Meeting of the International Health Regulations (2005) Emergency Committee regarding the Outbreak of Novel Coronavirus (2019-nCoV)", $30 \mathrm{de}$ enero de de 2020, https:/ / www.who.int/news-room/detail/30-01-2020-sta tement-on-the-second-meeting-of-the-international-health-regulations(2005)-emergency-committee-regarding-the-outbreak-of-novel-coronavi rus-(2019-ncov) (consulta del 15 de enero de 2021). 
la cual la oms determinó que había alcanzado el estatus de pandemia el 11 de marzo del mismo año. ${ }^{51}$

En México, la epidemia es larga y difícil de controlar, debido a un sistema de salud fragmentado, ${ }^{52}$ descoordinado y con falta de horizontalidad, en medio de un proceso de reforma y una política de austeridad. ${ }^{53}$ Asimismo, el virus ha demostrado ser más letal en adultos mayores y personas con diabetes y obesidad, comorbilidades altas entre la población del país. ${ }^{54}$ En julio de 2020, la oms recomendó al gobierno mexicano que aumentara su capacidad de diagnóstico y elevara la aplicación de pruebas de detección del virus conocidas como PCR por su siglas en inglés. De hecho, el porcentaje de pruebas mostró un incremento de $15000 \%$. Aun así, México es uno de los que menos pruebas ha aplicado, aproximadamente 150 por cada 1000000 de habitantes, ${ }^{55}$ y para marzo de 2021 , México reportaba más de 2000000 de casos, con una mortalidad que ha fluctuado entre $10 \%$ y $8.5 \%$, colocándose como el tercer país con más personas fallecidas en el planeta. ${ }^{56}$

${ }^{51}$ Organización Mundial de la Salud, oms, "Director-General's Opening Remarks at the Media Briefing on COVID-19-11 March 2020", 11 de marzo de 2020, https://www.who.int/dg/speeches/detail/who-director-ge neral-s-opening-remarks-atthe-media-briefing-on-Covid-19-11-march2020 (consulta del 15 de enero de 2021).

${ }^{52}$ Karla Sánchez, "Entrevista a Laura Flamand. 'Un sistema de salud universal contribuiría a disminuir las desigualdades acentuadas por la pandemia'", Letras Libres, 1 de mayo de 2020.

${ }^{53}$ Jorge E. Culebro, art. cit., p. 46; José Eduardo Orellana Centeno, "El Coronavirus 19 (COVID 19) en México", Revista Chilena de Salud Pública, vol. 24, núm. 1, 2020, p. 72; María Esther Morales-Fajardo y Cecilia Cadena-Inostroza, "(Des) organizando la (des) gobernanza en tiempos de pandemia”, Notas de coyuntura del CRIM, núm. 6, 2020, p. 4.

${ }^{54}$ Celso Ramos, "Covid-19: la nueva enfermedad causada por un coronavirus", Revista de Salud Pública de México, vol. 62, núm. 2, 2020, p. 226; Ranferi Aragón-Nogales, Iván Vargas-Almanza y María Guadalupe Miranda-Novales, "COVID-19 por SARS-CoV-2: la nueva emergencia de salud", Revista Mexicana de Pediatría, vol. 86, núm. 6, 2019, pp. 213-218.

${ }^{55}$ Our World in Data, "Coronavirus Pandemic (COVID-19)", https:/ / ourworldindata.org/coronavirus (consulta del 20 de febrero de 2021).

${ }^{56}$ Loc.cit. 
Se podría decir que la respuesta inicial del gobierno fue cautelosa, cuando se llevó a cabo una primera reunión formal para discutir el brote celebrada el 30 de enero con el Comité Nacional para la Seguridad en Salud, en la que participó el asesor internacional de Emergencias en Salud de la oms. ${ }^{57}$ Aunque se detectó el primer caso en el país el 27 de febrero, ${ }^{58}$ fue hasta después de la declaración de pandemia de la oms, el 18 de marzo, cuando se reunieron miembros del gabinete legal y ampliado con los comités nacionales de Emergencias y de Seguridad en Salud, que presiden los secretarios de Seguridad y Protección Ciudadana, y de Salud. ${ }^{59}$ La respuesta oficial se dio a conocer el día siguiente con la publicación del Acuerdo del Consejo de Salubridad General (CSG), en el cual se reconoció la epidemia en México, y que estableció los mecanismos de respuesta. ${ }^{60}$ Bajo dicho acuerdo, la Secretaría de Salud federal asumió el liderazgo nacional y, el 30 de marzo, presentó ante el CSG las medidas de seguridad sanitaria para enfrentar la pandemia. El acuerdo destacó que las acciones del país se basarían en la información proporcionada por la oMs y los expertos internacionales. ${ }^{61}$

Según los estudios sobre comunidades epistémicas y redes transgubernamentales presentados en apartados anteriores, la presencia de miembros de redes de expertos en

${ }^{57}$ Secretaría de Salud, "Se reúne de forma extraordinaria el Comité Nacional para la Seguridad en Salud", 30 de enero de 2020, https://www. gob.mx/salud/prensa/se-reune-de-forma-extraordinaria-el-comite-nacio nal-para-la-seguridad-en-salud?idiom=es (consulta del 26 de enero de 2021).

58 "Coronavirus en México: confirman los primeros casos de Covid-19 en el país", $B B C, 29$ de febrero de 2020.

${ }^{59}$ Ernestina Álvarez, "Se reúnen comités nacionales de Emergencia y Seguridad en Salud por Covid-19", mvs Noticias, 19 de marzo de 2020.

60 "Primera reunión del Consejo de Salubridad General por coronavirus", Diario Contra Réplica, 19 de marzo de 2020.

${ }^{61}$ Secretaría de Gobernación, "Acuerdo por el que el Consejo de Salubridad General reconoce la epidemia de enfermedad por virus SARSCoV2 en México, como una enfermedad grave de atención prioritaria, así como se establecen las actividades de preparación y respuesta ante dicha epidemia”, Diario Oficial de la Federación, 19 de marzo de 2020. 
una administración incrementa la adopción y el cumplimiento de las políticas y lineamientos derivados de la gobernanza global en situaciones de crisis, como con la pandemia de la Covid-19. En el caso de México, al contar como parte de estas redes a actores como el subsecretario de Prevención y Promoción de la Salud, líder de la respuesta nacional, debería incrementarse la difusión y adopción de políticas globales a nivel nacional. Sin embargo, se observa que aquellos miembros directamente conectados a las redes transgubernamentales son también aquellos que tienen un posicionamiento doble, como expertos y como burócratas, y quienes han usado posicionamientos técnicos para legitimar decisiones políticas, sin seguir realmente las recomendaciones globales. ${ }^{62}$ Esto se ha observado para políticas que abarcan desde el ámbito económico hasta el de salud pública. Al mismo tiempo, han surgido comunidades epistémicas rivales a nivel nacional que han polemizado la estrategia del gobierno, donde destaca el grupo de exsecretarios de Salud, entre los que se encuentra el Dr. Julio Frenk, experto con reputación internacional y altamente conectado a la comunidad epistémica global. ${ }^{63}$

La legitimidad del conocimiento científico es lo que hace que la sociedad lo acepte ampliamente, sin embargo, algunos autores reconocen que la ciencia puede tener motivación política. ${ }^{64}$ En el caso de México, a pesar de que el acuerdo del CSG avala la posición de expertos a las personas a cargo del manejo de la situación, con base en su conocimiento científico, es importante considerar que en medio del cambio político que se vive en el país, el sistema presidencialista sigue dominando la toma de decisiones. A lo largo de la pandemia,

62 Jorge E. Culebro, art. cit., p. 50.

63 Salomón Chertorivski, et al., La gestión de la pandemia en México: análisis preliminar y recomendaciones urgentes, Ciudad de México, Consejo Consultivo Ciudadano Pensando en México, 2020.

64 William Clark y Giandomenico Majone, "The Critical Appraisal of Scientific Inquiries with Policy Implications", Science, Technology and Human Values, vol. 10, núm. 3, 1985, pp. 6-19. 
el presidente claramente ha marcado la pauta para determinar cuáles acciones se seguirán o no en el país. Una muestra de ello fue la decisión de implementar una reapertura temprana de la economía, haciendo caso omiso de lineamientos publicados el 12 de mayo por la oms, que estableció que una epidemia está controlada cuando se alcanza una tasa de positividad (el número de caso positivos en relación con el número de pruebas hechas) por debajo del 5\%.65 En México, sin embargo, la finalización de la Jornada Nacional de Sana Distancia, a partir del 30 de mayo, significó un proceso gradual de reapertura económica del sector formal -ya que el distanciamiento social no fue realmente impuesto de manera coercitiva a nivel individual-. ${ }^{66}$ Esto mientras la tasa de positividad ha fluctuado entre 40 y $50 \%$, desde la primera persona contagiada y, casi un año después, el país no ha podido aplanar la curva de casos. ${ }^{67}$ Muchos acusan al presidente por no haber permitido que se establecieran medidas más estrictas de confinamiento y por hacer declaraciones constantes en las que ha minimizado la pandemia ${ }^{68}$ como cuando en febrero del 2020 declaró que los mexicanos debían seguir visitando restaurantes, contrario a todo lo que se venía recomendando a nivel internacional. ${ }^{69}$

${ }^{65}$ Organización Mundial de la Salud, oms, "Public Health Criteria to Adjust Public Health and Social Measures in the Context of covid-19", 12 de mayo de 2020, https://www.who.int/publications/i/item/publicheal th-criteria-to-adjust-public-health-and-social-measures-in-the-context -of-Covid-19 (consulta del 15 de enero de 2021).

${ }^{66}$ Guillermo de Anda-Jáuregui, "Covid-19 in Mexico: A Network of Epidemics", borrador (e-print) en Física y Sociedad, archivo abierto no dictaminado, Universidad de Cornell, sometido el 20 de junio de 2020, p. 2, https://arxiv.org/abs/2006.11635 (consulta del 22 de septiembre de 2020).

${ }^{67}$ Our World in Data, "Mexico: Coronavirus Pandemic Country Profile", https://ourworldindata.org/coronavirus/country/mexico?country= MEX (consulta del 16 de enero de 2021).

68 "Los pecados originales que prolongan la pandemia en México", $E l$ Mañanero Diario, 23 de julio de 2020.

${ }^{69}$ Talha Burki, "COvid-19 in Latin America", The Lancet, vol. 20, núm. 5, 2020 , p. 547. 
El grupo de expertos que trabaja para el gobierno ha aceptado implícitamente las actuaciones del presidente por encima de las recomendaciones internacionales. Un ejemplo es la resistencia a implementar el uso generalizado de cubrebocas indicado desde el 5 de junio de $2020^{70}$ por la oms, con base en la evidencia científica que muestra sus ventajas para toda la población. ${ }^{71}$ Sin embargo, en México se recomendó el uso del cubrebocas de forma amplia hasta muy avanzada la pandemia. Para el líder nacional de la respuesta, este tipo de equipo de protección da una "falsa sensación de seguridad", e insistió en que otras medidas tales como mantener la distancia de otras personas y lavarse constantemente las manos son más importantes. ${ }^{72}$ La decisión se dio además en medio de la controversia del 24 de julio cuando el presidente declaró que él no portaba cubrebocas porque no estaba científicamente demostrada su utilidad y porque los expertos responsables del manejo en la pandemia en México no se lo sugerían. ${ }^{73}$ Aunque en noviembre de 2020 se reconoció la importancia del cubrebocas, el encargado de la respuesta nacional solamente apoyó que se emitiera una recomendación de su uso, más no su obligatoriedad, justificando el abuso de autoridad de gobiernos anteriores, ${ }^{74}$ argu-

${ }^{70}$ Centros para el Control y la Prevención de Enfermedades de Estados Unidos, CDC, "Coronavirus Disease", 2020, https://www.cdc.gov/coro navirus/2019-ncov/ (consulta del 15 de enero de 2021).

${ }^{71}$ Organización Mundial de la Salud, oms, "Advice on the Use of Masks in the Context of Covid-19", Interim Guidance, 5 de junio 2020; Kar Chen Keung, Tai Hing Lam y Chi Chiu Leung, "Wearing Face Masks in the Community during the Covid-19 Pandemic: Altruism and Solidarity", The Lancet, 16 de abril de 2020.

72 "López-Gatell: Polémicas del subsecretario que lleva las riendas ante Covid-19", El Heraldo de México, 15 de enero de 2021.

${ }^{73}$ Alexis Pavón, "No está científicamente demostrado que cubrebocas evite el contagio de Covid-19: MLO”, SDP Noticias, 24 de julio de 2020.

${ }^{74}$ María Fernanda Navarro, "Obligar uso de cubrebocas pone en riesgo derechos humanos: López-Gatell”, Forbes, 12 de agosto de 2020; “LópezGatell pide a medios difundir uso de cubrebocas, luego de decir que no era eficaz", Animal Político, 18 de noviembre de 2020. 
mento consistente con la ideología política del gobierno actual, mismo que no se basa en la evidencia científica. ${ }^{75}$

También es importante reconocer que otras medidas representan un gran reto para México, como la escasez de agua potable y la importancia del sector informal en la economía. Si bien es cierto que se reconoció la problemática del agua al inicio de la pandemia, el Dr. López-Gatell depositó la responsabilidad en estados y municipios, aun cuando la oms y otras organizaciones internacionales han expresado que garantizar el acceso a este recurso es de suma importancia para luchar contra epidemias. ${ }^{76}$ De nuevo, el argumento político parece superar al problema técnico. En cuanto a la "sana distancia" y quedarse en casa, hay que destacar que la mayoría de los contagios se están dando en zonas altamente pobladas, donde abunda el comercio informal, con salarios bajos, lo que hace que las personas estén menos dispuestas a permanecer en casa, haciendo la distancia social difícil. ${ }^{77}$ Por esta razón, es cuestionable que no se haya apoyado más fuertemente el uso de cubrebocas, basada en evidencia científica y aceptada por la comunidad epistémica internacional, y que es altamente relevante en el contexto de México.

Otro aspecto importante de la politización de la gestión de la pandemia ha sido el uso de las conferencias diarias para comunicar la información sobre la respuesta a la epidemia en el país y que han servido para legitimar al gobierno actual, a través del responsable de la respuesta a la pandemia y experto de la comunidad epistémica. ${ }^{78}$ Como tales, estas

75 Carlos Perusquía, “Considera AmLo ‘autoritario' hacer obligatorio el uso de cubrebocas”, AM Queretaro, 16 de noviembre de 2020.

76 Otto Bettsy, et al., "Agua: el aliado clave en la lucha contra el coronavirus”, WRI México, 15 de abril de 2020.

77 Rachel Chang, Jonshan Hong y Kevin Varley, "The Covid Resilience Ranking”, Bloomberg, 21 de diciembre de 2020.

78 Ninón Irene Llano Guibarra y Julio César Águila Sánchez, "Conferencias de prensa y Covid-19: explorando la respuesta gubernamental 
conferencias no han sido exclusivas para presentar la respuesta técnica, sino que se han usado para promover acciones para enfrentar la pandemia como aciertos políticos. Un caso destacado fue el anuncio presidencial de la designación del Dr. López-Gatell a la lista de expertos del RSI, un hecho sin precedente dado que anteriormente muchos otros expertos han sido nombrados a esta lista sin semejante visibilidad política. Al mismo tiempo se minimizó el nombramiento de la Dra. Celia Alpuche, del Instituto Nacional de Salud Pública, como miembro del Grupo de Expertos en Asesoramiento Estratégico (SAGE) sobre las vacunas Covid-19, para el periodo de junio de 2020 a diciembre de $2021 .{ }^{79}$ Ambas designaciones son de igual importancia y deberían haber sido presentadas como logros de la red de expertos nacionales. La forma en que la información se trató oficialmente, sin embargo, favoreció principalmente la imagen del experto nacional a cargo de la pandemia y personaje central de la respuesta del gobierno.

Una parte del problema que se genera por acciones como la mencionada es que se ha creado un ambiente de división en la comunidad epistémica y la red transgubernamental. Las fragmentaciones han sido amplificadas por el gobierno al no aceptar críticas ni entrar en un diálogo con aquellos que piensan diferente, a pesar de ser expertos directamente conectados en la red transgubernamental, mientras que se exalta y reafirma que la estrategia nacional se basa en evidencia científica. Además, esto se refleja en cómo varias de las decisiones que los expertos del gobierno han tomado continúan siendo severamente cuestionadas por la falta de congruencia con las medidas recomendadas desde lo global. Lo anterior ha originado que varios expertos nacionales, entre ellos algunos exsecretarios de salud, externen su preocupación por la es-

mexicana desde la comunicación en salud", Revista Española de Comunicación en Salud, sup. 1, 2020, p. S138.

79 "La Dra. Celia Alpuche se integra al Grupo de Expertos en Asesoramiento Estratégico de la oms", comunicado del Instituto Nacional de Salud Pública (INSP), 9 de julio 2020. 
trategia, criticando el manejo de la epidemia y presentando una serie de recomendaciones para hacer cambios en el mismo. ${ }^{80}$ Ante esto, la respuesta del subsecretario López-Gatell fue desacreditar dichas recomendaciones y criticar a este grupo, cuestionando su experiencia como servidores públicos y como expertos, ${ }^{81}$ lo cual además alimenta el discurso de que todo crítico de la estrategia nacional tiene intereses políticos específicos y se opone al proyecto del gobierno actual, la denominada Cuarta Transformación. ${ }^{82}$ Esta posición, adoptada desde el gobierno, debilita la capacidad de la comunidad epistémica para tener una mayor influencia en la difusión de las políticas globales.

De la misma manera, otros expertos han criticado la falta de pruebas, la falta de datos, la desorganización de la información y las disparidades entre las cifras que tienen los estados y la federación, poniendo en duda los números de casos del gobierno. ${ }^{83}$ De esta forma, podría considerarse la existencia de grupos antagonistas o rivales a los expertos del gobierno, ya que interpretan de forma distinta las recomendaciones provenientes de la oms. Ante la falta de un consenso en la comunidad nacional, se afecta su legitimi-

${ }^{80}$ Ernestina Álvarez, "Exsecretarios de Salud advierten que actuación de gobierno ante Covid-19 es confusa", mvs Noticias, 7 de mayo 2020; "Exsecretarios de salud y médicos llaman a no relajar medidas sanitarias", Milenio, 3 de julio de 2020.

81 "López-Gatell arremetió contra exsecretarios de Salud: "nunca se familiarizaron con la vigilancia epidemiológica', Infobae, 24 de septiembre de 2020; “'Fórmulas mágicas': así fue como López-Gatell describió el plan de exsecretarios de salud para contener la epidemia”, Infobae, 10 de septiembre 2020.

82 "Critica AMLO a quienes 'se vuelven expertos', desinforman y mienten sobre coronavirus", Aristegui Noticias, 13 de marzo 2020; "Fórmulas mágicas"”, art. cit.

${ }^{83}$ Sandra Weiss, "México está tan mal como Brasil en su lucha contra la pandemia", DW, 16 de agosto de 2020; David Agren, "Mexico Flying Blind as Lack of Covid-19 Testing Mystifies Experts", The Guardian, 24 de julio de 2020; Arturo Daen, "Los vigilantes: expertos en datos evalúan la forma en que Salud ha informado sobre Covid-19 en México", Animal Político, 5 de mayo de 2020. 
dad, la población recibe mensajes discordantes y decide adoptar medidas de acuerdo con sus propios intereses y posibilidades.

Los ejemplos anteriormente expuestos denotan los problemas que las comunidades epistémicas tienen para difundir y transferir políticas globales. En el caso de México, el doble papel de los expertos que trabajan desde el gobierno ha llevado a conflictos dentro de la comunidad y contradicciones que han entorpecido una mejor respuesta ante la Covid-19. Esto además considerando que al cierre de esta investigación los expertos gubernamentales siguen presentando una estrategia que no ha sido modificada, a pesar de contar con retroalimentación de la comunidad nacional que podría integrarse para cambiar el rumbo de la situación.

\section{Conclusiones}

En la gobernanza global de la salud, las comunidades epistémicas y redes transgubernamentales son mecanismos importantes que ayudan a la transferencia y difusión de políticas creadas en el ámbito global. Sus conexiones facilitan la difusión de normas y la transmisión de información. Aunque las redes de expertos tienen capacidad de influir en las políticas públicas en todos los niveles, existen factores de su estructura interna y de la forma en que se conectan al proceso de toma de decisiones que puede limitar esta capacidad. Con el caso de México confirmamos que los actores nacionales vinculados a las redes de expertos han enfrentado problemas ante la falta de cohesión y de consensos de su comunidad, así como ante la interferencia política, que cuestiona su legitimidad. Este trabajo reafirma que existe una línea muy delgada entre el poder y el conocimiento, y que grupos de expertos pueden usar su papel de autoridades en un tema para promover una ideología política aun cuando ésta no resuene con la ciencia. Aunque el gobierno de México ha adoptado ciertas recomendaciones internacionales, también 
ha decidido poner menos énfasis en medidas que se han probado efectivas, como el uso de cubrebocas, un confinamiento obligatorio y el cierre total de la actividad económica. A pesar de que muchos argumenten que se han hecho lo necesario, las cifras de casos y muertos reflejan algo distinto.

Lo crítico del caso mexicano, así como el de otros países que han decidido adoptar medidas guiadas más por motivos políticos que por la evidencia científica es, por una parte, la forma en que se está desacreditando las políticas globales derivadas de una comunidad que ha tratado de luchar contra un problema que afecta a todos por igual. Por otra parte, al seguir imponiendo un modelo de toma de decisiones basado en los intereses estatales, aun cuando se enfrentan fenómenos que requieren una respuesta global coordinada, se relega la actuación de actores no estatales, que son indispensables para enfrentar problemas globales como las pandemias.

El análisis de la experiencia con la Covid-19 en varios contextos permitirá reevaluar el funcionamiento de las comunidades epistémicas y de las redes transgubernamentales como proveedores de evidencia científica en la toma de decisiones. Asimismo, será importante poner a prueba si el papel doble de experto y el responsable de tomar decisiones es importante para su efectividad o si es más importante promover mecanismos con expertos conectados a los gobiernos únicamente a través de actores globales, como los organismos internacionales.

\section{REFERENCIAS BIBLIOGRÁFICAS}

Agren, David, "Mexico Flying Blind as Lack of Covid-19 Testing Mystifies Experts", The Guardian, 24 de julio de 2020, https:// www.theguardian.com/global-development/2020/jul/24/ mexico-Covid-19-testing-coronavirus (consulta del 30 de enero de 2021).

Alexander, George L. and Andrew Bennetr, Case Studies and Theory Development in Social Sciences, Cambridge, MIT Press, 2005. 
Álvarez, Ernestina, "Se reúnen comités nacionales de Emergencia y Seguridad en Salud por Covid-19", mvs Noticias, 19 de marzo de 2020, https://mvsnoticias.com/noticias/nacionales/se-reu nen-comites-nacionales-de-emergencia-y-seguridad-en-saludpor-Covid-19/ (consulta del 10 de enero de 2021).

Álvarez, Ernestina, "Exsecretarios de Salud advierten que actuación de gobierno ante Covid-19 es confusa", mvs Noticias, 7 de mayo 2020, en https:/ / mvsnoticias.com/noticias/nacionales/ ex-secretarios-de-salud-advierten-que-actuacion-de-gobiernoante-covid-19-es-confusa/ (consulta del 20 de enero de 2021). Anda-Jáuregui, Guillermo de, "Covid-19 in Mexico: A Network of Epidemics", borrador (e-print) en Física y Sociedad, archivo abierto no dictaminado, Universidad de Cornell, sometido el 20 de junio de 2020, https:/ /arxiv.org/abs/2006.11635 (consulta del 22 de septiembre de 2020).

Antoniades, Andreas, "Epistemic Communities, Epistemes and the Construction of World Politics", Global Society, vol. 17, núm. 1, 2003, pp. 21-38.

Aragón-Nogales, Ranferi, Iván Vargas-Almanza y María Guadalupe Miranda-Novales, "Covid-19 por sars-CoV-2: la nueva emergencia de salud", Revista Mexicana de Pediatría, vol. 86, núm. 6, 2019, pp. 213-218.

Behrmann, Savannah y Jeanine Santucai, "Here's a Timeline of President Donald Trump's and Dr. Anthony Fauci's Relationship", USA Today, 28 de octubre de 2020, en https:/ / www.usato day.com/story/news/politics/2020/10/28/president-donaldtrump-anthony-fauci-timeline-relationship-coronavirus-pan demic/3718797001/ (consulta del 25 de enero de 2021).

Burki, Talha, "COVID-19 in Latin America", The Lancet, vol. 20, núm. 5, 2020, pp. 547-548.

Centros para el Control y la Prevención de Enfermedades de Estados Unidos, CDC, "Coronavirus Disease", 2020, https://www. cdc.gov/coronavirus/2019-ncov/ (consulta del 15 de enero de 2021).

Chang, Rachel, Jinshan Hong y Kevin Varley, "The Covid Resilience Ranking”, Bloomberg, el 21 de diciembre de 2020, https: / / 
www.bloomberg.com/graphics/covid-resielience-ranking (consulta del 10 de enero de 2021).

Chertorivski, Salomón, et al., La gestión de la pandemia en México: análisis preliminar y recomendaciones urgentes, Ciudad de México, Consejo Consultivo Ciudadano Pensando en México, 2020.

Clark, William y Giandomenico Majone, "The Critical Appraisal of Scientific Inquiries with Policy Implications", Science, Technology and Human Values, vol. 10, núm. 3, 1985, pp. 6-19.

"Coronavirus en México: confirman los primeros casos de Covid-19 en el país”, ввс, 29 de febrero de 2020, https://www.bbc.com/ mundo/noticias-america-latina-51677751 (consulta del 10 de enero de 2021).

Cozzens, Susan y Edward Woodhouse, "Science, Government, and the Politics of Knowledge", en Sheila Jasanoff, et al. (eds.), Handbook of Science and Technology Studies, Thousand Oaks, Sage Publications, 1995, pp. 532-553.

"Critica AMLO a quienes 'se vuelven expertos', desinforman y mienten sobre coronavirus”, Aristegui Noticias, 13 de marzo 2020, https:/ / aristeguinoticias.com/1303/mexico/critica-amlo-aquienes-desinforman-se-vuelven-expertos-y-mienten-sobre-coronavirus/ (consulta del 25 de enero de 2021).

Culebro, Jorge E., "Gestión de crisis y retos para el sistema de salud. La coordinación vertical y horizontal para los sistemas de salud en México", Reporte CESOP, núm. 132, 2020, pp. 44-52.

Daen, Arturo, "Los vigilantes: expertos en datos evalúan la forma en que salud ha informado sobre Covid-19 en México", Animal Político, 5 de mayo de 2020, https://www.animalpolitico.com/ 2020/05/salud-datos-pandemia-expertos-covid-coronavirus / (consulta del 30 de enero de 2021).

Davis Cross, Mai'a K., "Rethinking Epistemic Communities Twenty Years Later”, Review of International Studies, vol. 39, núm. 1, 2013, pp. 137-160.

Davis Cross, Mai'a K., Security Integration in Europe: How KnowledgeBased Networks Are Transforming the European Union, Ann Arbor, University of Michigan Press, 2011. 
Evans, Mark, "Understanding Policy Transfer", en Mark Evans (ed.), Policy Transfer in Global Perspective, Aldershot, Ashgate, 2004, pp. 10-42.

"Ex secretarios de salud y médicos llaman a no relajar medidas sanitarias", Milenio, 3 de julio de 2020, https://www.milenio. com/politica/Covid-19-secretarios-salud-piden-relajar-medi das (consulta del 26 de enero de 2021).

Fleming, Nic, "Coronavirus Misinformation, and How Scientists Can Help to Fight it", Nature, 17 de junio de 2020, https://www. nature.com/articles/d41586-020-01834-3 (consulta del 25 de enero de 2021).

“'Fórmulas mágicas': así fue como López-Gatell describió el plan de exsecretarios de salud para contener la epidemia”, Infobae, 10 de septiembre 2020, https://www.infobae.com/america/ mexico/2020/09/10/formulas-magicas-asi-fue-como-lopezgatell-describio-el-plan-de-ex-secretarios-de-salud-para-conte ner-la-epidemia/ (consulta del 30 de enero de 2021).

Frenk, Julio y Sue Moon, "Governance Challenges in Global Health”, New England Journal of Medicine, vol. 368, núm. 10, 2013, pp. 936-942.

HaAs, Peter, "Epistemic Communities and International Policy Coordination”, International Organization, vol. 46, núm. 1, 1992, pp. 1-35.

HaAs, Peter, "When Does Power Listen to Truth? A Constructivist Approach to the Policy Process", Journal of European Public Policy, vol. 11, núm. 4, 2004, pp. 569-592.

HaAs, Peter, Epistemic Communities, Constructivism, and International Environmental Politics, Nueva York, Routledge, 2015.

Hallal, Pedro C., "SOS Brazil: Science under Attack", The Lancet, vol. 397, núm. 10272, 2021, pp. 373-374.

Horton, Richard, "Offline: Science and Politics in the Era of COVID-19”, The Lancet, vol. 396, núm. 10259, 2020, p. 1319. Jenson, Jane, "Diffusing Ideas for After Neoliberalism: The Social Investment Perspective in Europe and Latin America”, Global Social Policy, vol. 10, núm. 1, 2010, pp. 59-84.

Karlsson, Michael, "Epistemic Communities and Cooperative Security: The Case of Communicable Disease Control in the Bal- 
tic Sea Region”, Journal of International and Area Studies, vol. 11, núm. 1, 2004, pp. 79-100.

Keck, Margaret y Kathryn Sikkink, "Transnational Advocacy Networks in International and Regional Politics", en Activists Beyond Borders, Ithaca, Cornell University Press, 1998, pp. 1-38.

Keung, Kar Chen, Tai Hing Lam y Chi Chiu Leung, "Wearing Face Masks in the Community during the COVID-19 Pandemic: Altruism and Solidarity", The Lancet, 16 de abril de 2020, https:/ / www.thelancet.com/journals/lancet/article/PIIS01406736(20)30918-1/fulltext (consulta del 20 de enero de 2021).

Krebs, Ronald R., "The Limits of Alliance: Conflict, Cooperation, and Collective Identity", en Anthony Lake y David Ochmanek (eds.), The Real and the Ideal: Essays on International Relations in Honor of Rich, Lanham, Rowman \& Littlefield Publishers, 2001, pp. 207-235.

"La Dra. Celia Alpuche se integra al Grupo de Expertos en Asesoramiento Estratégico de la oms", comunicado del Instituto Nacional de Salud Pública (INSP), 9 de julio 2020, https://www. insp.mx/avisos/5434-grupo-expertos-asesoramiento-estrategi co-oms.html (consulta del 20 de enero de 2021).

LeE, Kelly y Adam Kamradt-Scott, "The Multiple Meanings of Global Health Governance: A Call for Conceptual Clarity”, Globalization and Health, vol. 11, 2014, pp. 10-28.

Legrand, Timothy, "Sovereignty Renewed: Transgovernmental Policy Networks and the Global Local Dilemma", en Diane Stone y Kim Moloney (eds.), Global Policy and Transnational Administration, Oxford, University Press, 2019, pp. 200-222.

Legrand, Timothy, "Transgovernmental Policy Networks in the Anglosphere”, Public Administration, vol. 93, núm. 4, 2015, pp. 973-991.

Llano Guibarra, Ninón Irene y Julio César Águila Sánchez, "Conferencias de prensa y COVID-19: explorando la respuesta gubernamental mexicana desde la comunicación en salud", Revista Española de Comunicación en Salud, sup. 1, 2020, pp. S128-S141.

"López-Gatell: polémicas del subsecretario que lleva las riendas ante Covid-19”, El Heraldo de México, 15 de enero de 2021, 
https://heraldodemexico.com.mx/nacional/2021/1/15/lo pez-gatell-polemicas-del-subsecretario-que-lleva-las-riendas-an te-covid-19-244970.html (consulta del 20 de enero de 2021).

"López-Gatell pide a medios difundir uso de cubrebocas, luego de decir que no era eficaz", Animal Político, 18 de noviembre de 2020, https://www.animalpolitico.com/2020/11/lopez-gatellmedios-difundir-uso-cubrebocas/ (consulta del 26 de enero de 2021).

"López-Gatell arremetió contra ex secretarios de Salud: 'nunca se familiarizaron con la vigilancia epidemiológica'”, Infobae, 24 de septiembre de 2020, en https://www.infobae.com/america/ mexico/2020/09/24/lopez-gatell-arremetio-contra-ex-secreta rios-de-salud-que-criticaron-la-estrategia-covid-nunca-se-familia rizaron-con-la-vigilancia-epidemiologica/ (consulta del $30 \mathrm{de}$ enero de 2021).

López-Ortiz, Eduardo, et al., "From the Handling of an Outbreak by an Unknown Pathogen in Wuhan to the Preparedness and Response in the Face of the Emergence of Covid-19 in Mexico", Gaceta Médica de México, vol. 156, núm. 2, 2020, pp. 132-137.

"Los pecados originales que prolongan la pandemia en México", El Mañanero Diario, 23 de julio de 2020, https:/ /www.elmanan erodiario.com/los-pecados-originales-prolongan-la-pande mia-mexico/ (consulta del 26 de enero de 2021).

Majone, Giandomenico, Evidence, Argument, and Persuasion in the Policy Process, New Haven, Yale University Press, 1989.

Mandavilli, Apoorva, "W.H.O. to Review Evidence of Airborne Transmission of Coronavirus", The New York Times, 6 de julio de 2020, https://www.nytimes.com/2020/07/07/health/coronavi rus-aerosols-who.html?action=click\&module=RelatedLinks\&pg type=Article (consulta del 20 de febrero de 2021).

Mc. Niel, Donald, "Un zorrillo en el picnic: Anthony Fauci habla de cómo fue trabajar para Trump", The New York Times, 26 de enero de 2021, https://www.nytimes.com/es/2021/01/26/ espanol/entrevista-fauci-trump.html (consulta del 26 de enero de 2021). 
Morawska, Lidia y Donald K. Milton, "It Is Time to Address Airborne Transmission of Coronavirus Disease 2019 (COVID-19)", Clinical Infectious Diseases, vol. 71, núm. 9, 2020, pp. 2311-2313. Morales-Fajardo, María Esther y Cecilia Cadena-Inostroza, "(Des) organizando la (des) gobernanza en tiempos de pandemia”, Notas de coyuntura del CRIM, núm. 6, 2020, pp. 1-4.

Morin, Jean-Frédéric, "Paradigm Shift in the Global IP Regime: The Agency of Academics", Review of International Political Economy, vol. 21, núm. 2, 2014, pp. 275-309.

Navarro, María Fernanda, "Obligar uso de cubrebocas pone en riesgo derechos humanos: López-Gatell”, Forbes, 12 de agosto de 2020, https://www.forbes.com.mx/politica-obligar-cubrebo cas-riesgo-derechos-humanos-lopez-gatell/ (consulta del 26 de enero de 2021).

Orellana, José Eduardo, "El Coronavirus 19 (Covid 19) en Mexico", Revista Chilena de Salud Pública, vol. 24, núm. 1, 2020, pp. 73-74.

Organización Mundial de la Salud, oms, "Advice on the Use of Masks in the Context of COVID-19", Interim Guidance, 5 de junio 2020, https://apps.who.int/iris/bitstream/handle/10665 /332293/WHO-2019-nCov-IPC_Masks-2020.4-eng.pdf? sequence=1\&isAllowed =y (consulta del 10 de enero de 2021).

Organización Mundial de la Salud, oms, "Status of Collection of Assessed Contributions, Including Member States in Arrears in the Payment of their Contributions to an Extent that Would Justify Invoking Article 7 of the Constitution", Resolución A72/23, 2020, p. 8, https://apps.who.int/gb/ebwha/pdf_files/ WHA73/A73_26-en.pdf (consulta del 30 de enero de 2021).

Organización Mundial de la Salud, oms, "Public Health Criteria to Adjust Public Health and Social Measures in the Context of COVID-19", 12 de mayo de 2020, https://www.who.int/publica tions/i/item/public-health-criteria-to-adjust-public-healthand-social-measures-in-the-context-of-Covid-19 (consulta del 15 de enero de 2021).

Organización Mundial de la Salud, oms, "Director-General's Opening Remarks at the Media Briefing on COVID-19", 11 de marzo de 2020, https://www.who.int/dg/speeches/detail/who-direc 
tor-general-s-opening-remarks-atthe-media-briefing-on-Covid19-11-march-2020 (consulta del 15 de enero de 2021).

Organización Mundial de la Salud, oms, "Statement on the Second Meeting of the International Health Regulations (2005) Emergency Committee regarding the Outbreak of Novel Coronavirus (2019-nCoV)", 30 de enero de 2020, https://www.who.int/ news-room/detail/30-01-2020-statement-on-the-second-meet ing-of-the-international-health-regulations-(2005)-emergencycommittee-regarding-the-outbreak-of-novel-coronavirus-(2019ncov) (consulta del 15 de enero de 2021).

Organización Mundial de la Salud, oms, Report of the Review Committee on the Functioning of the International Health Regulations (2005) about Pandemic Influenza (H1N1) 2009, Documento A64/105, mayo de 2011.

Organización Mundial de la Salud, oms, Strengthening Response to Pandemics and other Public Health Emergencies, Documento A64/ 10, IHR Review Committee, 2011.

Organización Mundial de la Salud, oms, Reglamento Sanitario Internacional 2005, Ginebra, 2008.

Organización Mundial de la Salud, oms/Panel de Expertos Independientes, Report of the Ebola Interim Assessment Panel, julio de 2015.

Отто, Bettsy, et al., "Agua: el aliado clave en la lucha contra el coro navirus”, WRI México, 15 de abril de 2020, https://wrimexico. org/bloga/agua-el-aliado-clave-en-la-lucha-contra-el-coronavi rus (consulta del 26 de enero de 2021).

Our World in Data, "Coronavirus Pandemic (COVID-19)", https:/ / ourworldindata.org/coronavirus (consulta del 26 de febrero de 2021).

Our World in Data, "Mexico: Coronavirus Pandemic Country Profile) https://ourworldindata.org/coronavirus/country/mexi co? country= MEX (consulta del 16 de enero de 2021).

Pavón, Alexis, "No está científicamente demostrado que cubrebocas evite el contagio de Covid-19: AMLO", SDP noticias, 24 de julio de 2020, https://www.sdpnoticias.com/nacional/amlono-esta-cientificamente-comprobado-cubrebocas-ayude-con 
tagios-coronavirus-Covid-19.html (consulta del 26 de enero de 2021).

Payne, A. M.-M., "The Influenza Programme of WHO", Bulletin World Health Organization, núm. 8, 1953, pp. 755-774.

Perusquía, Carlos, “Considera Amlo 'autoritario' hacer obligatorio el uso de cubrebocas", AM Queretaro, 16 de noviembre de 2020, https://amqueretaro.com/politica-nacional/2020/11/ 16/considera-amlo-autoritario-hacer-obligatorio-el-uso-de-cu brebocas/ (consulta del 26 de enero de 2021).

"Primera reunión del Consejo de Salubridad General por coronavirus", Diario Contra Réplica, 19 de marzo de 2020, https://www. contrareplica.mx/nota-Primera-reunion-del-Consejo-de-Salu bridad-General-por-coronavirus202019355 (consulta del 12 de enero de 2021).

Ramos, Celso, "Covid-19: la nueva enfermedad causada por un coronavirus", Revista de Salud Pública de México, vol. 62, núm. 2, 2020, pp. 225-227.

"López-Gatell, nuevo miembro del comité de expertos de la oms", Aristegui Noticias, 12 de junio de 2020, https:/ / aristeguinoticias. com/1206/mexico/lopez-gatell-nuevo-miembro-del-comitede-expertos-de-la-oms/ (consulta del 26 de enero de 2021).

SÁnchez, Karla, "Entrevista a Laura Flamand. 'Un sistema de salud universal contribuiría a disminuir las desigualdades acentuadas por la pandemia'”, Letras Libres, 1 de mayo de 2020, https:/ / www.letraslibres.com/mexico/revista/entrevista-laura-fla mand-un-sistema-salud-universal-contribuiria-disminuir-lasdes igualdades-acentuadas-por-la-pandemia (consulta del 26 de enero de 2021).

Sebenius, James y David A. Lax, "Interests: The Measure of Negotiation”, Negotiation Journal, vol. 2, núm. 1, 1986, pp. 73-92.

Sebenius, James K., "Challenging Conventional Explanations of International Cooperation: Negotiation Analysis and the Case of Epistemic Communities", International Organization, vol. 46, núm. 1, 1992, pp. 323-365.

Secretaría de Gobernación, Segob, "Acuerdo por el que el Consejo de Salubridad General reconoce la epidemia de enfermedad por virus sars-CoV2 en México, como una enfermedad 
grave de atención prioritaria, así como se establecen las actividades de preparación y respuesta ante dicha epidemia”, Diario Oficial de la Federación, 19 de marzo de 2020.

Secretaría de Salud, "Se reúne de forma extraordinaria el Comité Nacional para la Seguridad en Salud", 30 de enero de 2020, https://www.gob.mx/salud/prensa/se-reune-de-forma-ex traordinaria-el-comite-nacional-para-la-seguridad-en-salud? idiom=es (consulta del 26 de enero de 2021).

Sending, Ole J., "Knowledge Networks, Scientific Communities, and Evidence-Informed Policy", en Diane Stone and Kim Moloney (eds.), The Oxford Handbook of Global Policy and Transnational Administration, Oxford, University Press, 2019, pp. 383-400.

Shiffman, Jeremy, et al., "A Framework on the Emergence and Effectiveness of Global Health Networks", Health Policy and Planning, vol. 31, sup. 1, 2016, pp. i3-i16.

Skogstad, Grace, "Legitimacy and/or Policy Effectiveness? Network Governance and GMO Regulation in the European Union”, Journal of European Public Policy, vol. 10, núm. 3, 2003, pp. 323-327.

Slaughter, Anne-Marie y David T. Zaring, "Networking Goes International: An Update”, Annual Review of Law E Social Science, vol. 2, 2006, pp. 211-229.

Späтн, Konrad, "Inside Global Governance: New Borders of a Concept", en Markus Lederer y Philipp Muller (eds.), Criticizing Global Governance, Nueva York, Palgrave Macmillan, 2005, pp. 21-44.

Stevens, Alex, "Survival of the Ideas that Fit: An Evolutionary Analogy for the Use of Evidence in Policy", Social Policy and Society, vol. 6, núm. 1, 2007, pp. 25-35.

Stone, Diane, "Transfer and Translation of Policy", Policy Studies, vol. 33, núm. 6, 2011, pp. 483-499.

Stone, Diane y Stella Ladi, "Global Public Policy and Transnational Administration", Public Administration, vol. 93, núm. 4, 2015, p. 839-855.

Toke, David, "Epistemic Communities and Environmental Groups", Politics, vol. 19, num. 2, 1999, pp. 97-102. 
Underdal, Arild, "Explaining Compliance and Defection: Three Models", European Journal of International Relations, vol. 4, núm. 1, 1998, pp. 5-30.

Weiss, Sandra, “'México está tan mal como Brasil en su lucha contra la pandemia'”, $D w, 16$ de agosto de 2020, https:/ / p.dw.com/ p/3h2TZ (consulta del 26 de enero de 2021).

Wendt, Alexander, "Anarchy Is What States Make of It: The Social Construction of Power Politics", International Organization, vol. 46, núm. 2, 1992, pp. 391-425.

Weyland, Kurt, "The Puzzle of Policy Diffusion", Bounded Rationality and Policy Diffusion: Social Sector Reform in Latin America, Princeton, University Press, 2006, pp. 1-29.

Youde, Jeremy, "The Development of a Counter-Epistemic Community: AIDS, South Africa, and International Regimes", International Relations, vol. 19, núm. 4, 2005, pp. 421-439.

Zacher, Mark W. y Tania J. KeEfe, The Politics of Global Health Governance. United by Contagion, Nueva York, Palgrave Macmillan, 2007. 
